(C) 2018, The Authors. Published by FASS Inc. and Elsevier Inc. on behalf of the American Dairy Science Association ${ }^{\circledR}$. This is an open access article under the CC BY license (http://creativecommons.org/licenses/by/4.0/).

\title{
Immune-associated traits measured in milk of Holstein- Friesian cows as proxies for blood serum measurements
}

\author{
Scott J. Denholm, ${ }^{* 1}$ Tom N. McNeilly, $\dagger$ Georgios Banos, ${ }^{*} \ddagger$ Mike P. Coffey, ${ }^{*}$ George C. Russell, $\dagger$ \\ Ainsley Bagnall, ${ }^{*}$ Mairi C. Mitchell, $\dagger$ and Eileen Wall* \\ *Scotland's Rural College (SRUC), Peter Wilson Building, Kings Buildings, West Mains Road, Edinburgh EH9 3JG, United Kingdom \\ †Moredun Research Institute, Pentlands Science Park, Midlothian EH26 OPZ, United Kingdom \\ ¥The Roslin Institute, The University of Edinburgh, Easter Bush, Midlothian EH25 9RG, United Kingdom
}

\begin{abstract}
Previous work has highlighted that immune-associated (IA) traits measurable in blood are associated with health, productivity, and reproduction in dairy cows. The aim of the present study was to determine relationships between IA traits measured in blood serum and those simultaneously measured in milk as well as their association with disease phenotypes. All animals were Holstein-Friesian cows from the Langhill research herd $(\mathrm{n}=546)$ housed at the SRUC Dairy Research Centre in Scotland. Milk and serum samples were collected on 20 separate occasions between July 2010 and March 2015 and analyzed by ELISA for haptoglobin (Hp), tumor necrosis factor- $\alpha$ (TNF- $\alpha$ ), and natural antibodies binding keyhole limpet hemocyanin $\left(\mathrm{NAb}_{\mathrm{KLH}}\right)$ and lipopolysaccharide $\left(\mathrm{NAb}_{\mathrm{LPS}}\right)$. Data were analyzed using mixed linear models that included pedigree information. Analyses revealed positive phenotypic correlations between milk and serum NAb $(0.59 \leq \mathrm{r} \leq 0.77)$, Hp ( $=0.37)$, and TNF- $\alpha(\mathrm{r}=0.12)$. Milk and serum NAb were also found to have a strong genetic correlation $(0.81 \leq \mathrm{r} \leq 0.94)$ and were genetically correlated with cow lameness $\left(0.66\right.$ and 0.79 for milk $\mathrm{NAb}_{\mathrm{KLH}}$ and serum $\mathrm{NAb}_{\mathrm{LPS}}$, respectively). Clinical mastitis was found to be phenotypically correlated with both milk and serum Hp $(0.09 \leq \mathrm{r} \leq 0.23)$. Serum Hp was also strongly genetically correlated with other cellular IA traits such as percent $\mathrm{NKp}_{4} 6^{+}$(a natural killer cell marker; 0.35) and percent peripheral blood mononuclear cells (PBMC; $-0.90)$. Similarly, genetic correlations were found to exist between serum TNF- $\alpha$ and percent NKp46 $6^{+}(0.22)$, percent PBMC (0.41), and percent lymphocytes (0.47). Excluding serum Hp, all milk and serum IA traits were repeatable, ranging from 0.11 (milk $\mathrm{Hp)}$ ) to 0.43 (serum $\left.\mathrm{NAb}_{\text {LPS }}\right)$. Between-animal variation was highest in milk
\end{abstract}

Received March 26, 2018.

Accepted July 13, 2018.

${ }^{1}$ Corresponding author: scott.denholm@sruc.ac.uk and serum NAb (0.34-0.43) and significant estimates of heritability were also observed in milk and serum NAb (0.17-0.37). Our findings show that certain IA traits, such as $\mathrm{NAb}_{\mathrm{KLH}}$ and $\mathrm{NAb}_{\mathrm{LPS}}$, found in milk and serum are strongly correlated and highlight the potential of using routinely collected milk samples as a less invasive and cost-effective source of informative data for predictive modeling of animal IA traits.

Key words: natural antibody, immune-associated trait, correlation, dairy cow

\section{INTRODUCTION}

Animal health and welfare is an important issue, especially in the case of farmed animals involved in intensive production systems such as the modern highyielding dairy cow. Maintaining a healthy herd is vital, both ethically and financially. The UK dairy industry is under increasing financial pressure due to the cost of production against the lower level of returns generated via milk sales (Colman and Harvey, 2004; Bate, 2016; ADHB, 2017). Further financial losses and pressures emerge in the form of animal disease, culling, and infertility within the herd. With greater cow-to-staff ratios and increased use of automation it is crucial for dairy farmers to record, monitor, and manage losses due to disease and resultant culling and hence maximize profitability (Macrae and Esslemont, 2015).

The prospect of using immune-associated (IA) traits as markers of health and fitness in agricultural production systems has attracted increasing interest due the fact that such traits are readily measurable and can be used in the prediction of susceptibility and general immunity of individuals (Clapperton et al., 2008, 2009; Flori et al., 2011; Thompson-Crispi et al., 2012a,b; van Knegsel et al., 2012; Banos et al., 2013; Denholm et al., 2017). Moreover, previous work has shown that serological and cellular IA traits found in serum are associated with dairy cow health, fertility, and production (Eckersall et al., 2006; Banos et al., 2013; Denholm et al., 2017). 
Serological IA traits such as the acute phase protein (APP) haptoglobin (Hp), natural antibodies (NAb)

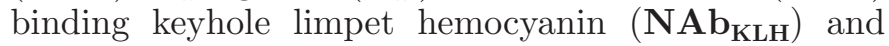
lipopolysaccharide $\left(\mathbf{N A} \mathbf{b}_{\mathbf{L P S}}\right)$, and the pro-inflammatory cytokine tumor necrosis factor- $\alpha$ ( TNF- $\alpha)$ are not only present in the blood of dairy cows but can also be measured in the milk (Bannerman et al., 2004; Eckersall et al., 2006; van Knegsel et al., 2007; Tassi et al., 2013). These serum IA traits have been shown to be associated with important health and production traits in dairy cows; for example, serum Hp is positively correlated with clinical mastitis (Eckersall et al., 2006), whereas circulating levels of $\mathrm{NAb}_{\mathrm{KLH}}$ are negatively correlated with liveweight as well as both feed and dry matter intake (Banos et al., 2013). Additional studies have linked NAb with dairy cow health; for example, energy balance, SCC, and mastitis (van Knegsel et al., 2007, 2012; Ploegaert et al., 2010), as well as production; for example, milk yield and diet (van Knegsel et al., 2007). Relationships between NAb and age have also been highlighted (Srinivasan et al., 1999; van Knegsel et al., 2007; de Klerk et al., 2015). Furthermore, serum TNF- $\alpha, \mathrm{Hp}$, and NAb have all been shown to be associated with metabolic health (Ohtsuka et al., 2001; Ametaj et al., 2005; van Knegsel et al., 2012)

Focusing on NAb, Hp, and TNF- $\alpha$, we aimed to analyze longitudinal immunological data collected from repeated blood and milk sampling to determine whether any relationships exist between IA traits measurable in blood (serum) and concurrent IA traits measurable in milk. The overall objective was to determine whether routinely collected milk samples could provide a less invasive method of obtaining useful IA trait data relevant to dairy cow health and productivity, and hence, reduce the requirement for blood sampling.

\section{MATERIALS AND METHODS}

\section{Animals}

Data were collected from 546 Holstein-Friesian dairy cows from the experimental Langhill herd between July 2010 and March 2015. All cows were raised at the SRUC Dairy Research Centre at Crichton Royal Farm (Dumfries, Scotland) and were involved in a longrunning and ongoing selection experiment, genetic line $\times$ feeding system, following a $2 \times 2$ factorial design (Veerkamp et al., 1994).

Within the Langhill herd, cows are evenly distributed between 2 distinct genetic lines: Control and Select. Cows in the Control line are progeny of sires with UK average genetic merit for production of kilograms of milk fat plus protein, whereas Select cows are progeny of sires with the highest genetic merit for kilograms of milk fat plus protein. Within each genetic group, cows are randomly assigned 1 of 2 diets: a high-concentrate low-forage diet simulating high-input commercial systems; and a low-concentrate high-forage diet simulating low-input grazing systems. Put simply, the 2 diets can be thought of as a high-energy content feed (low forage) and a lower-energy content feed (high forage; March et al., 2016).

Concerning the animals involved in the present study, $46 \%$ were cows sampled as part of a previous pilot study by our group. These pilot study cows (n = 253) were born between January 2003 and March 2009 and were between their first and sixth lactations inclusive (Banos et al., 2013). All remaining cows ( $\mathrm{n}=$ 358) were born between May 2007 and September 2012 and ranged from first and fifth lactation (inclusive). A small number of cows $(n=65)$ were contemporaneous with both studies.

\section{Ethics Statement}

Blood sample collection was conducted in accordance with UK Home Office regulations (PPL No: 60/4278 Dairy Systems, Environment and Nutrition) and procedures were approved by the SRUC Animal Experimentation Committee. Otherwise, the study was restricted to routine on-farm observations and measurements that did not inconvenience or stress the animals.

\section{Sampling Protocol}

Blood and milk samples were collected on 15 separate occasions between April 2013 and March 2015 and included summer and winter samplings. Samples were collected at 4 bimonthly (i.e., every other month) intervals between April 2013 and October 2013, 7 monthly intervals between January 2014 and July 2014, and a further 4 bimonthly intervals between September 2014 and March 2015. This resulted in 2,687 blood samples and 2,667 milk samples. Additional blood samples were collected previously as part of a pilot study, between July 2010 and March 2011, the methods of which are described by Banos et al. (2013). These additional samples accounted for approximately $25 \%$ (886 samples) of the total number of samples collected (6,240 samples, which included 3,581 blood samples and 2,667 milk samples). For serological analyses, whole blood was collected into plain Vacutainers (BD, Reading, UK) and allowed to coagulate before centrifugation at 2,000 $\times$ $g$ for 10 min. Milk was centrifuged at $3,000 \times g$ for 30 min and the skim milk fraction was retained. Samples were stored at $-20^{\circ} \mathrm{C}$ before analysis.

Blood and milk samples from the current study were analyzed by ELISA for natural antibodies $\left(\mathrm{NAb}_{\mathrm{KLH}}\right.$ and 
$\left.\mathrm{NAb}_{\mathrm{LPS}}\right), \mathrm{Hp}$, and TNF- $\alpha$ as described below. Samples from our previous study (Banos et al., 2013) had previously been analyzed for $\mathrm{NAb}_{\mathrm{KLH}}, \mathrm{Hp}$, and TNF- $\alpha$. Cellular IA trait data were derived according to the methods in Denholm et al. (2017).

\section{Measurement of NAb, Hp, and TNF- $\alpha$}

Natural antibodies binding either KLH or LPS were quantified by indirect ELISA in serum and skim milk as follows: microtiter plates (Immulon 2HB, Thermo Electron Corp., Milford, MA) were coated with 100 $\mu \mathrm{L} /$ well of either $1 \mu \mathrm{g} / \mathrm{mL}$ KLH (Calbiochem, Nottingham, UK) or $4 \mu \mathrm{g} / \mathrm{mL}$ LPS O55:B5 (Sigma-Aldrich, St. Louis, MO) in $0.1 M$ carbonate coating buffer at $\mathrm{pH}$ 9.6 overnight at $4^{\circ} \mathrm{C}$. After plates were washed in PBS, $\mathrm{pH}$ 7.4, containing $0.05 \%$ Tween 20 (PBS-T), nonspecific binding sites were blocked by incubating wells with PBS containing 3\% fish gelatin (Sigma-Aldrich) for $1 \mathrm{~h}$ at $37^{\circ} \mathrm{C}$. Plates were subsequently incubated with serum diluted 1:40 or skim milk diluted 1:2.5 in PBS-NaCl-Tween (PBS containing $0.5 \mathrm{M} \mathrm{NaCl}$ and $0.5 \%$ Tween 80 ) for $1 \mathrm{~h}$ at $37^{\circ} \mathrm{C}$. For each plate, 8 wells were incubated with PBS-NaCl-Tween alone (blank), a known positive control sample was analyzed, and each test sample was analyzed in duplicate. After washing in PBS-T, plates were incubated for $1 \mathrm{~h}$ at $37^{\circ} \mathrm{C}$ with sheep anti-bovine $\operatorname{IgG}\left(\mathrm{H}^{+} \mathrm{L}\right.$ chain) conjugated to horseradish peroxidase (AbD Serotec, Kidlington, UK) diluted in PBS-NaCl-T. After a final wash in PBS-T, color reactions were developed by addition of Sigma-Fast OPD substrate (Sigma-Aldrich). Reactions were terminated by addition of $2.5 \mathrm{M} \mathrm{H}_{2} \mathrm{SO}_{4}$, and the optical density (OD) at $492 \mathrm{~nm}\left(\mathrm{OD}_{492}\right)$ measured using a Sunrise microplate reader (Tecan, Mannedorf, Switzerland). The dilutions of serum and skim milk were chosen following serial dilution of representative samples to ensure that the $\mathrm{OD}_{492}$ for all samples was on the linear part of the curve. For each plate, the mean $\mathrm{OD}_{492}$ of the blank wells was subtracted from the sample readings, and inter-plate variation was normalized to the positive control sample.

Haptoglobin levels in serum and milk were quantified by sandwich ELISA as follows: 96-well microtiter plates were coated with $0.125 \mu \mathrm{g} / \mathrm{mL}$ rabbit anti-bovine $\mathrm{Hp}$ (Life Diagnostics Inc., West Chester, PA) in carbonate coating buffer overnight at $4^{\circ} \mathrm{C}$. Following washing in $0.02 M$ Tris-HCl, $0.05 \%$ Tween 20 (TBS-T), wells were incubated with $10 \%$ nonfat milk powder in wash buffer for $1 \mathrm{~h}$ at $37^{\circ} \mathrm{C}$. Following washing in TBS-T, wells were incubated with serum or skim milk samples, diluted 1:40 or 1:10 for serum and skim milk, respectively, for $1 \mathrm{~h}$ at $37^{\circ} \mathrm{C}$ with shaking (500 rpm). Eight serial dilutions of recombinant bovine haptoglobin standard (Life
Diagnostics Inc.) ranging from 8 to $1,025 \mathrm{ng} / \mathrm{mL}$ were included on each plate. After a further wash in TBS-T, plates were incubated with a 1:7,500 dilution of rabbit polyclonal anti-bovine haptoglobin (Life Diagnostics Inc.) that had been conjugated to alkaline phosphatase using a Lightning-Link Alkaline Phosphatase Labeling Kit (Innova Biosciences Ltd., Cambridge, UK). Plates were washed and then developed using BluePhos Microwell phosphatase substrate system (KPL, Gaithersburg, MD) for $15 \mathrm{~min}$ before stopping with APstop solution (KPL) and measuring OD at $620 \mathrm{~nm}$ using a Sunrise microplate reader (Tecan).

Tumor necrosis factor- $\alpha$ was quantified in serum and skim milk as previously described (Tassi et al., 2013). Both serum and milk samples were analyzed neat, and 8 serial dilutions of recombinant bovine TNF- $\alpha$ standard (R\&D Systems, Abingdon, UK) ranging from 125 to $8,000 \mathrm{pg} / \mathrm{mL}$ were included on each plate.

To quantify levels of Hp and TNF- $\alpha$, a 4-point Marquardt analysis of the standard curve was used to calculate concentrations within the samples. For Hp and TNF- $\alpha$, ELISAs were repeated at the lower or higher sample dilution if the sample OD did not fall within the range of OD of the standard curve. Samples that still fell below the standard curve were assigned a concentration half of the lowest standard (i.e., $4 \mathrm{ng} / \mathrm{mL}$ for $\mathrm{Hp}$ and $62.5 \mathrm{pg} / \mathrm{mL}$ for $\mathrm{TNF}-\alpha$ ).

There were some differences between the techniques used previously (Banos et al., 2013) and those used in the present study to take the blood and milk measures of the IA traits. For Hp and TNF- $\alpha$, the assays used in the present study differed from those in Banos et al. (2013). First, in the case of Hp, a colorimetric assay (Tridelta PHASE Haptoglobin Assay kit, Tridelta Development Ltd., Maynooth, Ireland) was used to generate data in Banos et al. (2013) instead of the inhouse ELISA used in this study. The main difference between the 2 assays was the smaller dynamic range of the colorimetric assay. Second, an in-house ELISA was used to quantify TNF- $\alpha$ in this study, whereas in Banos et al. (2013), a commercial ELISA kit was used (Bovine TNF- $\alpha$ DuoSet ELISA kit, R\&D Systems Inc., Minneapolis, MN); however, the same TNF standards were used in both assays and, as such, the values are comparable. There were no differences in the methods used to generate $\mathrm{NAb}_{\mathrm{KLH}}$ data between the 2 studies, although $\mathrm{NAb}_{\mathrm{LPS}}$ was not measured in Banos et al. (2013).

\section{Derivation of Health Traits}

Each cow in the study population had detailed longitudinal health records spanning birth to the time of the present study. These data were used to create a 
phenotypic data set matching the immune profile of each individual cow to relevant health event information. Health events were grouped into 3 groups: clinical mastitis, reproductive problems, and cow lameness. Because of the low incidence of some disorders and diseases within the Crichton herd (e.g., metabolic), these conditions (including ketosis, displaced abomasum, hypocalcemia, hypomagnesemia, and pyelonephritis) were grouped into a fourth group termed "other." Health and IA traits were matched such that animals were scored as 0 or 1 for absence or presence of a condition or treatment within $1 \mathrm{wk}$ (pre and post) of the sampling date for IA traits. Moreover, for each cow in the study, the number of distinct mastitis, reproductive, and lameness episodes per lactation was calculated and added to the phenotypic data set. Distinct episodes were calculated according to consecutive treatments more than 7, 21, and $28 \mathrm{~d}$ apart for mastitis, reproductive problems, and lameness, respectively (Banos et al., 2013; Denholm et al., 2017).

\section{Data Preparation}

When possible, all data were analyzed in their original raw format except in cases when data were not normally distributed, in which case transformations were applied. Milk and serum data for both $\mathrm{Hp}$ and TNF- $\alpha$ were highly positively skewed, and hence, Box-Cox transformation analyses were carried out to determine the optimum transformation required to achieve normality. The Box-Cox analyses yielded results close to zero; therefore, data relating to these traits underwent a log-transformation. In the case of milk and serum TNF- $\alpha$, values that were below the detection limit of the assay $(62.5 \times 0.5=31.25 \mathrm{pg} / \mathrm{mL})$ were set close to zero $\left(1 \times 10^{-11}\right)$ before being transformed according to a log-transformation. No transformations were applied to milk or serum NAb before formal analyses.

\section{Statistical Analysis}

All statistical analyses of IA traits were carried out using ASReml version 3 (Gilmour et al., 2009) using repeated-measures mixed linear animal models. In general, models were of the form in equation [1]:

$$
\mathbf{y}=\mathbf{X} \mathbf{a}+\mathbf{Z}_{1} \mathbf{b} \_\mathbf{a}+\mathbf{Z}_{2} \mathbf{b} \_\mathbf{w}+\mathbf{Z}_{3} \mathbf{c}+\mathbf{e},
$$

where $\mathbf{y}$ is a vector of trait observations; $\mathbf{a}$ is a vector of fixed effects; $\mathbf{b} \_\mathbf{a}$ is a vector of random permanent environmental effects across lactations; $\mathbf{b} \_\mathbf{w}$ is a vector of random permanent environmental effects within lactation; $\mathbf{c}$ is a vector of random additive genetic effects; $\mathbf{e}$ is a vector of random residual effects; and $\mathbf{X}, \mathbf{Z}_{1}$, $\mathbf{Z}_{2}$, and $\mathbf{Z}_{3}$ are incidence matrices linking phenotypic records to fixed, permanent environmental across lactations, permanent environmental within lactation, and additive genetic effects, respectively.

The general model included the following as fixed effects: genetic line, diet group, lactation week, year $\times$ month of record interaction, year $\times$ month of calving interaction, and lactation number $\times$ age at calving interaction. Assay technique was also fitted as a fixed effect (where applicable) to account for the variation between the methods used to generate IA trait data in Banos et al. (2013) and in the present study. Treatment status was fitted as a binary fixed effect to account for whether or not the individual cow was receiving medical treatments at time of IA trait sampling (where 0 represents no treatment and 1 otherwise). Cow was fitted as a random effect to account for the random additive genetic effect of the $n$th individual cow (including pedigree data for 2,793 animals). The permanent environmental effect of the $n$th individual cow was fitted as a random effect to account for repeated sampling of the same animal across and within lactation. A further random effect of lactation by permanent environmental effect (of the $n$th individual cow) interaction was also fitted to account for repeated sampling of the same animal within a lactation (Bormann et al., 2002; Carthy et al., 2015).

\section{Variance Components and Ratios}

Univariate models were used to estimate variance parameters and ratios. The model in [1] partitioned the variance into its additive genetic $\left(\sigma_{a}^{2}\right)$, permanent environmental $\left(\sigma_{p e}^{2}\right)$, and residual error $\left(\sigma_{e}^{2}\right)$ components. Variance components and corresponding standard errors were estimated via the REML approach using the statistical software ASReml version 3 (Gilmour et al., 2009). The ASReml outputs were used to calculate heritability $\left(h^{2}\right)$; repeatability; that is, the between-individual variance; and the ratio of permanent environmental variance to total phenotypic variance $\left(c^{2}\right)$ of milk and blood serological IA traits.

\section{Associations Between Defined Traits}

To investigate and determine associations between traits, bivariate, trivariate, and multivariate models were used. Univariate analysis of the general model [1] was used to determine which fixed effects to include in the $n$-trait models $(n=2,3,4)$. Additive genetic, phenotypic, permanent environmental, and residual 
Table 1. Descriptive statistics for the serum and milk immune-associated traits

\begin{tabular}{|c|c|c|c|c|c|}
\hline Sample & Trait $^{1}$ & No. of records & Mean & $\mathrm{SD}$ & CV (\%) \\
\hline \multirow[t]{4}{*}{ Serum } & $\mathrm{Hp}(\mu \mathrm{g} / \mathrm{mL})$ & 3,561 & 83.87 & 369.79 & 440.89 \\
\hline & $\mathrm{NAb}_{\mathrm{KLH}}$ & 2,687 & 0.94 & 0.30 & 31.79 \\
\hline & $\mathrm{NAb}_{\mathrm{LPS}}$ & 3,570 & 1.15 & 0.52 & 44.90 \\
\hline & TNF- $\alpha(\mathrm{pg} / \mathrm{mL})$ & 3,568 & $1,841.74$ & $6,435.26$ & 349.41 \\
\hline \multirow{4}{*}{ Milk } & $\mathrm{Hp}(\mu \mathrm{g} / \mathrm{mL})$ & 2,667 & 0.97 & 6.39 & 659.36 \\
\hline & $\mathrm{NAb}_{\mathrm{KLH}}$ & 2,667 & 0.81 & 0.35 & 43.84 \\
\hline & $\mathrm{NAb}_{\text {LPS }}$ & 2,667 & 0.34 & 0.24 & 71.61 \\
\hline & TNF- $\alpha(\mathrm{pg} / \mathrm{mL})$ & 2,667 & 103.29 & 375.23 & 363.29 \\
\hline
\end{tabular}

${ }^{1} \mathrm{Hp}=$ haptoglobin; $\mathrm{NAb}_{\mathrm{KLH}}=$ natural antibodies binding keyhole limpet hemocyanin; $\mathrm{NAb}_{\mathrm{LPS}}=$ natural antibodies binding LPS; TNF- $\alpha=$ tumor necrosis factor- $\alpha$.

correlations were calculated along with their corresponding standard errors via $n$-trait analyses of the general model in [1] without the random permanent environment within lactation effect fitted. This was due to problems with convergence (with sensible variance or covariance estimates). Because the variance, and subsequent parameters, from the univariate analyses (with both permanent environment terms fitted) had only a marginal effect on the variances, we used the single permanent environment (across all lactations) term in the multivariate analyses. Correlations between immune and health traits, including clinical mastitis, lameness, and reproductive disorders, were also investigated.

\section{RESULTS}

Summaries of the milk and serum serological IA traits are given in Table 1. On average, lower NAb levels were observed in milk than in serum. Natural antibody levels in milk were also seen to increase with lactation number. In serum, however, no significant effect of lactation was observed in $\mathrm{NAb}_{\mathrm{KLH}}$ and only a slight decrease in $\mathrm{NAb}_{\text {LPS }}$ was observed. Variability of IA traits (deter- mined by the coefficient of variation) ranged from 32 to $44 \%$ for $\mathrm{NAb}_{\mathrm{KLH}}, 45$ to $72 \%$ for $\mathrm{NAb}_{\mathrm{LPS}}, 441$ to $659 \%$ for $\mathrm{Hp}$, and 349 to $363 \%$ for TNF- $\alpha$. Trait variability was observed to be higher in milk than in serum for all IA traits in general (Table 1).

\section{Variance Components and Ratios}

Estimates of variance components of the defined milk and serum serological IA traits as well as corresponding variance ratios are presented in Table 2 and summarized below.

Natural Antibodies. In both milk and serum, genetic variation and permanent environmental variation were relatively small and close to zero (Table 2 ). Between-animal variation accounted for less than $50 \%$ of total phenotypic variance, and repeatability of $\mathrm{NAb}_{\text {LPS }}$ in milk (0.38) was less than in serum (0.43). Moreover, repeatability of NAb in both milk and serum was highly significant $(P<0.001$, Table 2$)$. Variance parameter calculations also yielded significant heritabilities for both milk and serum NAb (Table 2). In serum, $\mathrm{NAb}_{\mathrm{KLH}}$ and $\mathrm{NAb}_{\mathrm{LPS}}$ had heritability estimates of 0.21 and 0.24 , respectively $(P<0.01)$. Similarly, in

Table 2. Variance components and ratios of serum and milk serological immune-associated traits ${ }^{1}$

\begin{tabular}{|c|c|c|c|c|c|c|c|c|}
\hline Sample & Trait $^{2}$ & $\sigma_{a}^{2}$ & $\sigma_{p e_{-} a}^{2}$ & $\sigma_{p e_{-} w}^{2}$ & $\sigma_{e}^{2}$ & $\sigma_{p}^{2}$ & $h^{2}$ & Rep \\
\hline & $\mathrm{NAb}_{\mathrm{KLH}}$ & $\mathbf{0 . 0 5}(0.01)$ & $\mathbf{0 . 0 3}(0.01)$ & $\mathbf{0 . 0 2}(0.01)$ & $0.12(0.00)$ & $\mathbf{0 . 2 2}(0.01)$ & $0.21(0.05)$ & $\mathbf{0 . 3 4}(0.03)$ \\
\hline \multirow[t]{3}{*}{ Milk } & $\mathrm{Hp}(\mu \mathrm{g} / \mathrm{mL})$ & $0.14(0.11)$ & $0.08(0.12)$ & $\mathbf{0 . 5 3}(0.10)$ & $1.22(0.04)$ & $1.98(0.08)$ & $0.07(0.06)$ & $0.11(0.05)$ \\
\hline & $\mathrm{NAb}_{\mathrm{KLH}}$ & $\mathbf{0 . 0 1}(0.00)$ & $0.01(0.00)$ & $0.00(0.00)$ & $\mathbf{0 . 0 3}(0.00)$ & $\mathbf{0 . 0 5}(0.00)$ & $\mathbf{0 . 1 7}(0.07)$ & $\mathbf{0 . 3 4}(0.03)$ \\
\hline & $\mathrm{NAb}_{\text {LPS }}$ & $\mathbf{0 . 0 4}(0.01)$ & $0.00(0.01)$ & $0.00(0.00)$ & $0.06(0.00)$ & $\mathbf{0 . 1 1}(0.01)$ & $0.37(0.08)$ & $\mathbf{0 . 3 8}(0.04)$ \\
\hline
\end{tabular}

\footnotetext{
${ }^{1}$ Estimated variance components (additive genetic, $\sigma_{a}^{2}$; permanent environmental across lactations, $\sigma_{p e}^{2}$; permanent environmental within lactation, $\sigma_{p e}^{2}$; residual, $\sigma_{e}^{2}$; and total phenotypic, $\left.\sigma_{p}^{2}\right)$ of milk and serum immune-associated traits were obtained from univariate analyses. Ratios of additive genetic variance to total phenotypic variance (heritability, $h^{2}$ ) and individual animal variance to total phenotypic variance (repeatability across lactations, Rep) were calculated from variance components obtained from univariate analyses. Statistically significant values $(P<$ $0.05)$ are given in bold; standard errors are presented in parentheses.

${ }^{2} \mathrm{Hp}=$ haptoglobin; $\mathrm{NAb}_{\mathrm{KLH}}=$ natural antibodies binding keyhole limpet hemocyanin; $\mathrm{NAb}_{\mathrm{LPS}}=$ natural antibodies binding LPS; $\mathrm{TNF}-\alpha=$ tumor necrosis factor- $\alpha$.
} 
milk, $\mathrm{NAb}_{\mathrm{KLH}}$ and $\mathrm{NAb}_{\mathrm{LPS}}$ had heritability estimates of 0.17 and 0.37 , respectively $(P<0.05)$. Heritability and repeatability of $\mathrm{NAb}_{\mathrm{LPS}}$ were observed to be greater than that of $\mathrm{NAb}_{\mathrm{KLH}}$, regardless of whether measured in milk or serum.

Tumor Necrosis Factor- $\alpha$. Genetic variation did not contribute much to the total phenotypic variation; however, a significant contribution was observed in the permanent environmental variance within lactation (Table 2).

Between-animal variance accounted for up to $21 \%$ of total phenotypic variation. Repeatability of both milk and serum TNF- $\alpha$ was highly significant $(0.21$ and 0.11 for milk and serum, respectively; $P<0.01)$. Because of the small contribution of additive genetic variation, estimates of heritability were low and not significant in either milk or serum (0.02 and 0.04, respectively).

Haptoglobin. Similar to NAb and TNF- $\alpha$, the additive genetic variance component was small and did not contribute very much to the total phenotypic variance in serum (0.03) and was only slightly higher in milk (0.14). Between-animal variance was low and not significant in serum with a repeatability of $4 \%$, whereas in milk, between-animal variance accounted for a much larger proportion of total variance with an estimated repeatability of $11 \%$. Heritability of $\mathrm{Hp}$ in both serum and milk was low and nonsignificant (0.02 and 0.07 respectively).

\section{Associations Between Milk and Serum IA Traits}

Strong positive additive genetic correlations $(P<$ 0.01 , Table 3 ) were found between $\mathrm{NAb}_{\mathrm{KLH}}$ and $\mathrm{NAb}_{\mathrm{LPS}}$ in milk (0.88) and serum (0.99). Similarly high correlations were observed between milk and serum $\mathrm{NAb}_{\mathrm{KLH}}$ (0.84) and between milk and serum NAb $\mathrm{NPS}_{\text {LPS }}(0.94)$. Moreover, serum $\mathrm{NAb}_{\mathrm{KLH}}$ was positively correlated with milk $\mathrm{NAb}_{\mathrm{LPS}}(0.81)$, as were serum $\mathrm{NAb}_{\mathrm{LPS}}$ and milk $\mathrm{NAb}_{\mathrm{KLH}}(0.91)$. Similar strong positive phenotypic correlations $(P<0.01)$ were observed $(0.59-0.77)$.
Model outputs (Table 4) highlighted a highly significant $(P<0.01)$ positive phenotypic correlation between TNF- $\alpha$ concentrations in milk and serum (0.12) and Hp concentrations in milk and serum (0.37). Phenotypic associations $(P<0.05)$ between milk and serum $\mathrm{Hp}$ and milk NAb were also observed (0.15 for both $\mathrm{NAb}_{\mathrm{KLH}}$ and $\left.\mathrm{NAb}_{\mathrm{LPS}}\right)$.

\section{Associations Between Serological and Cellular IA Traits}

Multivariate analyses (5-trait) were carried out to determine whether any relationships exist between serological (milk and serum) and cellular IA traits. In serum (Table 4), significant negative genetic associations were found between $\mathrm{NAb}_{\mathrm{KLH}}$ and percent peripheral blood mononuclear cells (PBMC, -0.39) and between $\mathrm{NAb}_{\mathrm{LPS}}$ and percent eosinophils $(-0.64)$. A positive genetic correlation was observed between $\mathrm{NAb}_{\mathrm{KLH}}$ and percent neutrophils (0.50). Interestingly, $\mathrm{NAb}_{\mathrm{KLH}}$ had a negative association with percent lymphocytes $(-0.36)$, whereas $\mathrm{NAb}_{\mathrm{LPS}}$ had a positive association (0.15). Regarding $T N F-\alpha$, significant genetic correlations were observed with $\mathrm{NKp}^{+} 6^{+}(0.22)$, a natural killer cell marker; percent PBMC (0.41); and percent lymphocytes (0.47). A significant phenotypic association was observed between TNF- $\alpha$ and $\mathrm{CD} 4^{+}: \mathrm{CD} 8^{+}$ratio (0.36). Haptoglobin was found to have a strong, negative additive genetic correlation with percent PBMC $(-0.90)$ as well as a moderate, positive additive genetic correlation with NKp46 $6^{+}$(0.35). Remaining significant correlations between serum serological and cellular immune associated traits were low and are presented in Table 4.

In milk (Table 4), statistically significant correlations at the phenotypic level were found to exist between $\mathrm{NAb}_{\text {LPS }}$ and percent eosinophils $(-0.07), \mathrm{CD} 4^{+}: \mathrm{CD} 8^{+}$ ratio (-0.03), and $\mathrm{NKp}_{4} 6^{+}(0.10)$. Furthermore, $\mathrm{NAb}_{\mathrm{KLH}}$ was found to be significantly correlated at the phenotypic level with percent eosinophils and the $\mathrm{CD} 4^{+}: \mathrm{CD}^{+}$ratio $(-0.08$ and -0.05 respectively). A

Table 3. Results from a multivariate analysis of milk and serum natural antibodies ${ }^{1}$

\begin{tabular}{|c|c|c|c|c|}
\hline Immune-associated trait $^{2}$ & $\begin{array}{l}\mathrm{NAb}_{\mathrm{KLH}} \\
(\text { serum })\end{array}$ & $\begin{array}{l}\mathrm{NAb}_{\text {LPS }} \\
\text { (serum) }\end{array}$ & $\begin{array}{l}\mathrm{NAb}_{\mathrm{KLH}} \\
(\text { milk) }\end{array}$ & $\begin{array}{c}\mathrm{NAb}_{\text {LPS }} \\
(\text { milk })\end{array}$ \\
\hline $\mathrm{NAb}_{\mathrm{KLH}}$ (serum) & $0.21(0.05)$ & $0.99(0.09)$ & $0.84(0.09)$ & $0.81(0.12)$ \\
\hline $\mathrm{NAb}_{\text {LPS }}$ (serum) & $0.69(0.01)$ & $0.17(0.06)$ & $0.91(0.13)$ & $0.94(0.05)$ \\
\hline $\mathrm{NAb}_{\mathrm{KLH}}(\mathrm{milk})$ & $0.77(0.01)$ & $0.59(0.02)$ & $\mathbf{0 . 1 6}(0.05)$ & $0.88(0.10)$ \\
\hline $\mathrm{NAb}_{\text {LPS }}($ milk $)$ & $0.61(0.02)$ & $0.77(0.01)$ & $0.75(0.02)$ & $\mathbf{0 . 2 3}(0.07)$ \\
\hline
\end{tabular}

${ }^{1}$ Additive genetic and phenotypic correlations between milk and serum natural antibodies are shown. Heritabilities are presented on the diagonal and highlighted in bold with genetic and phenotypic correlations presented above and below the diagonal, respectively. All values were statistically significant and standard errors are presented in parentheses.

${ }^{2} \mathrm{NAb}_{\mathrm{KLH}}=$ natural antibodies binding keyhole limpet hemocyanin; $\mathrm{NAb}_{\mathrm{LPS}}=$ natural antibodies binding LPS. 


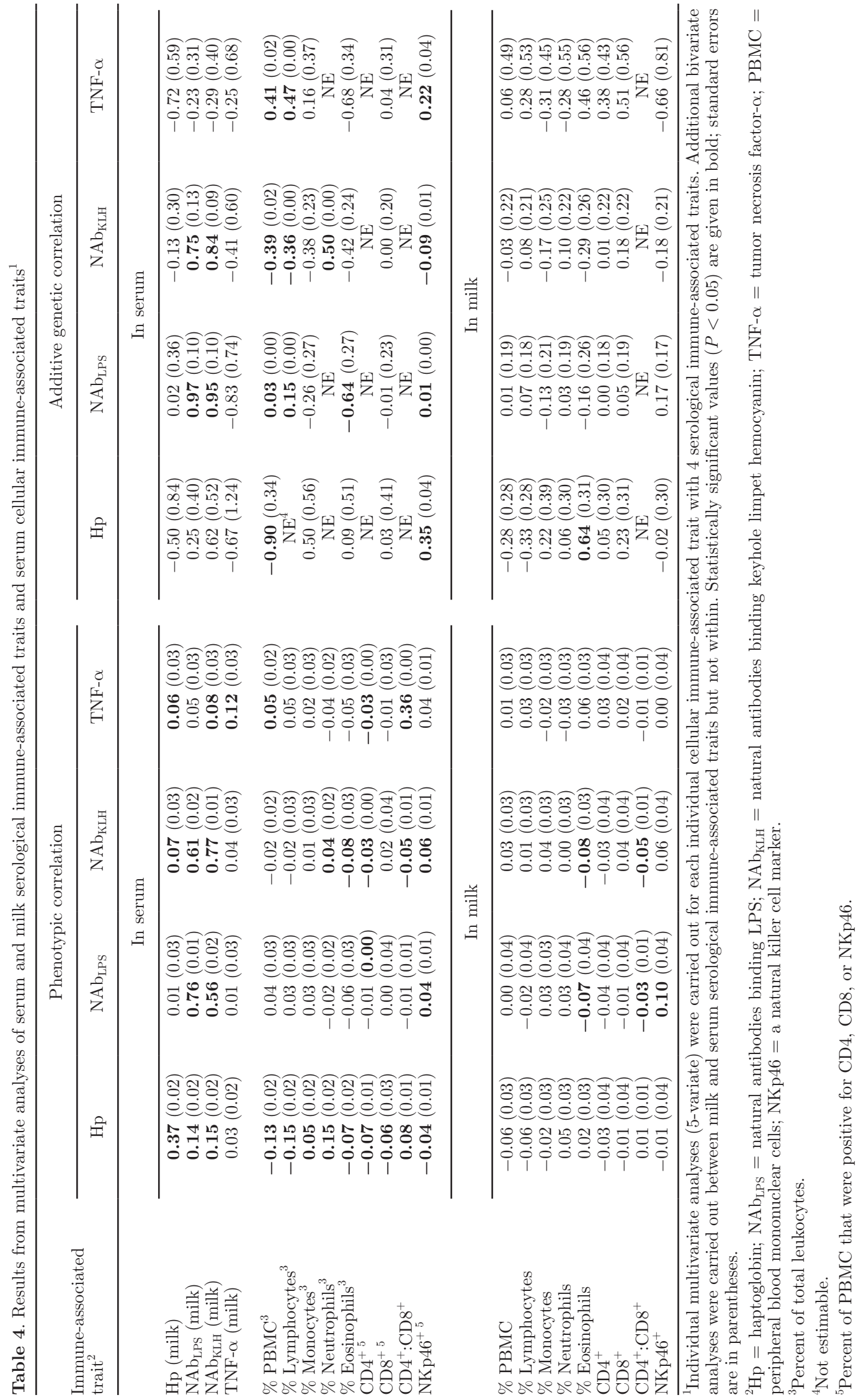


Table 5. Results from bivariate analyses of milk and serum serological immune-associated traits and health traits $^{1}$

\begin{tabular}{|c|c|c|c|}
\hline Health trait & Serological trait ${ }^{2}$ & Correlation $^{3}$ & SE \\
\hline Mastitis & TNF- $\alpha$ (milk) & 0.04 & 0.02 \\
\hline Mastitis & Hp (milk) & 0.15 & 0.02 \\
\hline Mastitis & Hp (serum) & 0.09 & 0.02 \\
\hline Reproductive problems & $\mathrm{NAb}_{\text {LPS }}$ (serum) & -0.03 & 0.02 \\
\hline Lameness & $\mathrm{NAb}_{\mathrm{KLH}}($ milk $)$ & 0.66 & 0.28 \\
\hline Lameness & $\mathrm{NAb}_{\mathrm{LPS}}$ (serum) & 0.79 & 0.28 \\
\hline Lameness & Hp (serum) & 0.05 & 0.02 \\
\hline Other health problems & Hp (serum) & 0.06 & 0.02 \\
\hline Mastitis episodes & Hp (milk) & 0.23 & 0.03 \\
\hline Mastitis episodes & Hp (serum) & 0.10 & 0.02 \\
\hline Reproductive problems episodes & TNF- $\alpha$ (serum) & -0.08 & 0.03 \\
\hline
\end{tabular}

${ }^{1}$ Phenotypic and additive genetic correlations observed between serum and milk serological immune-associated traits and health traits. Only phenotypic and additive genetic correlations that were statistically significant $(P<0.05)$ are presented.

${ }^{2} \mathrm{TNF}-\alpha=$ tumor necrosis factor- $\alpha ; \mathrm{Hp}=$ haptoglobin; $\mathrm{NAb}_{\mathrm{LPS}}=$ natural antibodies binding LPS; $\mathrm{NAb}_{\mathrm{KLH}}=$ natural antibodies binding keyhole limpet hemocyanin.

${ }^{3}$ All were phenotypic correlations except those for lameness with NAb $b_{K L H}$ and lameness with $\mathrm{NAb}_{\mathrm{LPS}}$ (additive genetic correlations).

strong additive genetic association was observed between milk Hp and percent eosinophils (0.64).

\section{Associations Between Serological IA Traits and Health Events}

Bivariate analyses (Table 5) yielded significant positive genetic correlations between NAb and lameness in the week of immune analysis $(0.66, P<0.05$; and 0.79 , $P<0.01$ for milk $\mathrm{NAb}_{\mathrm{KLH}}$ and serum $\mathrm{NAb}_{\mathrm{LPS}}$, respectively). Significant positive phenotypic correlations $(P$ $<0.001$ ) were observed between clinical mastitis and Hp (0.09 and 0.15 for serum and milk, respectively); and between mastitis episodes and $\mathrm{Hp}$ (0.10 and 0.23 for serum and milk, respectively).

\section{DISCUSSION}

The present study sought to determine the feasibility of using milk samples as a proxy for blood samples to more easily collect valuable trait information from dairy cows. Using routine milk samples to collect important and informative data is both less invasive to the cow and relatively inexpensive compared with collecting blood samples on a regular basis. In this study, four IA traits were investigated, $\mathrm{NAb}_{\mathrm{KLH}}, \mathrm{NAb}_{\mathrm{LPS}}, \mathrm{Hp}$, $\mathrm{TNF}-\alpha$, and a genetic analysis was performed.

\section{Natural Antibodies}

Significant additive genetic and phenotypic parameters as well as correlations were estimated between NAb levels measured in milk and serum. Natural antibodies are derived from $\mathrm{CD} 5^{+} \mathrm{B}-1$ cells (Casali and
Notkins, 1989) and are an important part of the innate immune system. Natural antibodies are found in all healthy animals in the absence of antigenic stimulation and are defined as antigen-binding antibodies present in nonimmunized individuals (Panda and Ding, 2015). They are characterized by broad antigen specificity, usually binding antigen with low affinity (Baumgarth et al., 2005). The premise for quantifying NAb binding KLH and LPS was that cows are highly unlikely to encounter KLH, which is derived from the hemolymph of the giant keyhole limpet, Megathura crenulata; therefore, NAb binding this antigen reflects the capacity of the innate antibody response to respond to pathogen challenge. In contrast, exposure to LPS is highly likely and thus NAb binding LPS may better reflect the active status of the innate humoral immune system (van Knegsel et al., 2007).

Levels of NAb in milk have been shown to increase with parity (van Knegsel et al., 2007; de Klerk et al., 2015), whereas no significant change in levels in blood have been observed (de Klerk et al., 2015). Furthermore, NAb levels are generally lower in milk than in blood (van Knegsel et al., 2007; Ploegaert and Tijhaar, 2011; de Klerk et al., 2015); results from the present study confirm these observations for both $\mathrm{NAb}_{\mathrm{KLH}}$ and $\mathrm{NAb}_{\mathrm{LPS}}$. From the genetic analysis, all milk and serum $\mathrm{NAb}$ were found to be repeatable $(P<0.01)$, agreeing with the results of Ploegaert and Tijhaar (2011), although estimates in the present study appear slightly lower than in Ploegaert and Tijhaar (2011). In both milk and serum, repeatability of $\mathrm{NAb}_{\mathrm{KLH}}$ was lower than that of $\mathrm{NAb}_{\mathrm{LPS}}$; Ploegaert and Tijhaar (2011) observed a similar trend in blood but not in milk. Moreover, heritability of $\mathrm{NAb}_{\mathrm{KLH}}$ in both milk and serum 
was similar in magnitude to that estimated by de Klerk et al. (2015). Furthermore, we found that heritability estimates of $\mathrm{NAb}_{\mathrm{KLH}}$ in serum (0.21) were higher than in milk (0.17), as was the case in de Klerk et al. (2015). In the case of $\mathrm{NAb}_{\mathrm{LPS}}$, however, we found the opposite was true, with higher heritability estimates seen in milk than in serum: 0.37 ( $h^{2}$ milk) and 0.24 ( $h^{2}$ serum).

Our analysis also highlighted that, at the genetic level, $\mathrm{Nab}_{\mathrm{KLH}}$ and $\mathrm{NAb}_{\mathrm{LPS}}$ in serum have a correlation of approximately 1 and, although these traits differed phenotypically $(0.61, P<0.01)$, they were always positively correlated (Table 3 ). The results of the analysis suggest that NAb in milk and serum are strongly and positively correlated, confirming the findings of other studies (Ploegaert and Tijhaar, 2011; de Klerk et al., 2015) and suggest that recording of milk NAb will provide accurate information on corresponding levels of $\mathrm{NAb}$ in serum. All phenotypic correlations were highly significant $(P<0.01)$ and in agreement with the literature (de Klerk et al., 2015). Genetic correlations ranged from 0.81 to 0.99 , similar to the results of de Klerk et al. (2015), indicating that selective breeding for one $\mathrm{NAb}$ type would have a strong influence on the other. Within milk, both $\mathrm{NAb}_{\mathrm{KLH}}$ and $\mathrm{NAb}_{\mathrm{LPS}}$ were found to be strongly correlated with phenotypic and genetic correlations of 0.54 to 0.58 and 0.85 to 0.93 , respectively. Genetic correlations were greater than phenotypic correlations, as in de Klerk et al. (2015).

Furthermore, we found genetic correlations between $\mathrm{NAb}_{\mathrm{KLH}}$ and percent PBMC $(-0.39)$ and percent lymphocytes $(-0.36)$, similar to findings in our smaller pilot study (Banos et al., 2013), which reported correlations of -0.29 for both percent $\mathrm{PBMC}$ and percent lymphocytes with $\mathrm{NAb}_{\mathrm{KLH}}$ but did not include pedigree information. We also identified significant positive genetic correlations for lameness episodes with both milk $\mathrm{NAb}_{\mathrm{KLH}}$ and serum NAb $\mathrm{b}_{\mathrm{LPS}}$. Together with our observations reported in Banos et al. (2013), in which serum $\mathrm{NAb}_{\mathrm{KLH}}$ was found to be negatively correlated with DMI, feed intake, and live weight at the phenotypic level, these data suggest that selection for low NAb levels, using either milk or serum measurements, may influence both nutritional traits and cow lameness.

\section{Haptoglobin}

Haptoglobin is an APP and part of the nonspecific innate immune response (Murata et al., 2004). It is a positive APP, meaning that concentrations of Hp become elevated as a result of external and internal challenges such as tissue damage, stress, and infectious and inflammatory disease (Murata et al., 2004; Lomborg et al., 2008). In healthy cattle, blood $\mathrm{Hp}$ is either nondetectable or measurable at very low concentrations (i.e.,
$<100 \mu \mathrm{g} / \mathrm{mL}$; Panndorf et al., 1976). Moreover, Smith at al. (2010) found cows that tested positive for Hp had concentrations ranging from 370 to $>1,000 \mu \mathrm{g} / \mathrm{mL}$.

The present study estimated a highly significant $(P$ $<0.01)$ phenotypic correlation between milk and serum levels (0.37), whereas the genetic correlation was found to be negative and not significant $(-0.50)$. From the literature, the phenotypic correlation between Hp measured in milk and blood has been estimated to be 0.6 (Hiss et al., 2009).

The present study also highlighted positive significant phenotypic correlations $(P<0.001)$ between $\mathrm{Hp}$ and clinical mastitis (0.09 and 0.15 for serum and milk, respectively), as well as between $\mathrm{Hp}$ and mastitis episodes ( 0.10 and 0.23 for serum and milk, respectively), suggesting that either milk or serum Hp could be used as a potential biomarker of bovine mastitis. These correlations, however, were much weaker than those found in a previous study by our group, which observed a phenotypic correlation between serum $\mathrm{Hp}$ and clinical mastitis of 0.32 (Banos et al., 2013). The difference in magnitude of the correlation in Banos et al. (2013) is most likely due to the inclusion of pedigree information in the present study, as well as to fitting a permanent environmental random effect. Moreover, whereas the previous results were obtained from data collected on 5 occasions, the present study made use of a much larger pool of data collected on 20 occasions, including 15 distinct sample periods, corresponding to a 4 -fold increase in records.

Serum Hp was found to have a positive genetic correlation with $\mathrm{NKp} 46^{+}(0.35)$, a natural killer cell marker (Sivori et al., 1997; Storset et al., 2004) that has been linked to reproductive outcome in both humans (Michou et al., 2003; Kwak-Kim and Gilman-Sachs, 2008; King et al., 2010; Seshadri and Sunkara, 2014) and cattle (Denholm et al., 2017).

\section{$T N F-\alpha$}

Tumor necrosis factor- $\alpha$ is a pro-inflammatory cytokine and is connected to many immune system cells including $\mathrm{B}$ and $\mathrm{T}$ lymphocytes and natural killer cells (Benedict et al., 2003); it plays a key role in the induction of the bovine acute phase response (Kushibiki et al., 2003).

Model analyses yielded a highly significant positive phenotypic correlation $(0.12, P<0.01)$ between milk and serum TNF- $\alpha$. Like serum Hp, serum TNF- $\alpha$ was found to be genetically predisposed to increase when circulating levels of NKp $46^{+}$were elevated. Significant positive genetic correlations were also found to exist with percent PBMC (0.41) and percent lymphocytes (0.47), both have been previously associated with milk 
fat percentage at the genetic level, such that levels are elevated with increasing milk fat (Denholm et al., 2017).

\section{CONCLUSIONS}

Outcomes from the genetic analysis in the present study suggest that immune-associated traits present in the milk of dairy cows are heritable and repeatable and have the potential to describe profiles in the blood, especially in the case of NAb. The strong genetic correlations found between milk and serum NAb suggest there is potential for using NAb in the milk as a marker for $\mathrm{NAb}$ in the blood. Furthermore, the relationships found among NAb, Hp, and TNF- $\alpha$ with both health and cellular IA traits are promising and warrant further study. Presently, milk samples are routinely collected for milk recording purposes and thus offer a less invasive and cost-effective way to sample and collect valuable and informative IA trait data for use in a variety of areas of predictive modeling.

\section{ACKNOWLEDGMENTS}

This research was funded by the Biotechnology and Biological Sciences Research Council (BBSRC, grant no., BB/K002260/1). The Langhill experiment at Crichton Dairy Research Centre and authors SJD, EW, TNMcN, MPC, and GCR are supported by the Scottish Government Rural Affairs, Food and the Environment (RAFE) Strategic Research Portfolio 2016-2021. The authors gratefully acknowledge all staff at Crichton farm (SRUC, Dumfries, UK) for collecting samples and managing animals. Ian Archibald (SRUC, Edinburgh, UK) is also gratefully acknowledged for managing the Langhill database and assisting with data extraction.

\section{REFERENCES}

ADHB. 2017. Estimated GB Milk Production Costs. Accessed Dec. 12, 2017. https://dairy.ahdb.org.uk/market-information/farming -data/estimated-gb-milk-production-costs.

Ametaj, B. N., B. J. Bradford, G. Bobe, R. A. Nafikov, Y. Lu, J. W. Young, and D. C. Beitz. 2005. Strong relationships between mediators of the acute phase response and fatty liver in dairy cows. Can. J. Anim. Sci. 85:165-175. https://doi.org/10.4141/A04-043.

Bannerman, D. D., M. J. Paape, J.-W. Lee, X. Zhao, J. C. Hope, and P. Rainard. 2004. Escherichia coli and Staphylococcus aureus elicit differential innate immune responses following intramammary infection. Clin. Diagn. Lab. Immunol. 11:463-472. https://doi.org/ 10.1128/CDLI.11.3.463-472.2004.

Banos, G., E. Wall, M. P. Coffey, A. Bagnall, S. Gillespie, G. C. Russell, and T. N. McNeilly. 2013. Identification of immune traits correlated with dairy cow health, reproduction and productivity. PLoS One 8:e65766. https://doi.org/10.1371/journal.pone .0065766 .

Bate, A. 2016. UK Dairy Industry Statistics. Accessed Nov. 21, 2016. http://researchbriefings.parliament.uk/ResearchBriefing/ Summary/SN02721.
Baumgarth, N., J. W. Tung, and L. A. Herzenberg. 2005. Inherent specificities in natural antibodies: A key to immune defense against pathogen invasion. Springer Semin. Immunopathol. 26:347-362. https://doi.org/10.1007/s00281-004-0182-2.

Benedict, C. A., T. A. Banks, and C. F. Ware. 2003. Death and survival: Viral regulation of TNF signaling pathways. Curr. Opin. Immunol. 15:59-65. https://doi.org/10.1016/S0952-7915(02)00018-3.

Bormann, J., G. R. Wiggans, T. Druet, and N. Gengler. 2002. Estimating effects of permanent environment, lactation stage, age, and pregnancy on test-day yield. J. Dairy Sci. 85:263.e1-263.e21. https://doi.org/10.3168/jds.S0022-0302(02)74076-9.

Carthy, T. R., D. P. Ryan, A. M. Fitzgerald, R. D. Evans, and D. P. Berry. 2015. Genetic parameters of ovarian and uterine reproductive traits in dairy cows. J. Dairy Sci. 98:4095-4106. https://doi .org/10.3168/jds.2014-8924.

Casali, P., and A. L. Notkins. 1989. CD5+ B lymphocytes, polyreactive antibodies and the human B-cell repertoire. Immunol. Today 10:364-368. https://doi.org/10.1016/0167-5699(89)90268-5.

Clapperton, M., A. B. Diack, O. Matika, E. J. Glass, C. D. Gladney, M. A. Mellencamp, A. Hoste, and S. C. Bishop. 2009. Traits associated with innate and adaptive immunity in pigs: Heritability and associations with performance under different health status conditions. Genet. Sel. Evol. 41:54. https://doi.org/10.1186/1297 -9686-41-54.

Clapperton, M., E. J. Glass, and S. C. Bishop. 2008. Pig peripheral blood mononuclear leucocyte subsets are heritable and genetically correlated with performance. Animal 2:1575-1584. https://doi .org/10.1017/S1751731108002929.

Colman, D., and D. Harvey. 2004. The Future of UK Dairy Farming. Accessed Nov. 21, 2016. http://webarchive.nationalarchives.gov .uk/20130822084033/http://www.defra.gov.uk/foodrin/milk/pdf/ colman-harveyreport.pdf.

de Klerk, B., B. J. Ducro, H. C. M. Heuven, I. den Uyl, J. M. van Arendonk, H. K. Parmentier, and J. J. van der Poel. 2015. Phenotypic and genetic relationships of bovine natural antibodies binding keyhole limpet hemocyanin in plasma and milk. J. Dairy Sci. 98:2746-2752. https://doi.org/10.3168/jds.2014-8818.

Denholm, S. J., T. N. McNeilly, G. Banos, M. P. Coffey, G. C. Russell, A. Bagnall, M. C. Mitchell, and E. Wall. 2017. Estimating genetic and phenotypic parameters of cellular immune-associated traits in dairy cows. J. Dairy Sci. 100:2850-2862. https://doi.org/10.3168/ jds.2016-11679.

Eckersall, P. D., F. J. Young, A. M. Nolan, C. H. Knight, C. McComb, M. M. Waterston, C. J. Hogarth, E. M. Scott, and J. L. Fitzpatrick. 2006. Acute phase proteins in bovine milk in an experimental model of Staphylococcus aureus subclinical mastitis. J. Dairy Sci. 89:1488-1501. https://doi.org/10.3168/jds.S0022-0302(06)72216 $-0$.

Flori, L., Y. Gao, D. Laloë, G. Lemonnier, J.-J. Leplat, A. Teillaud, A.-M. Cossalter, J. Laffitte, P. Pinton, C. de Vaureix, M. Bouffaud, M.-J. Mercat, F. Lefèvre, I. P. Oswald, J.-P. Bidanel, and C. Rogel-Gaillard. 2011. Immunity traits in pigs: Substantial genetic variation and limited covariation. PLoS One 6:e22717. https://doi .org/10.1371/journal.pone.0022717.

Gilmour, A., B. Gogel, B. Cullis, and R. Thompson. 2009. ASReml User Guide Release 3.0. VSN International Ltd., Hemel Hempstead, UK.

Hiss, S., C. Weinkauf, S. Hachenberg, and H. Sauerwein. 2009. Short communication: Relationship between metabolic status and the milk concentrations of haptoglobin and lactoferrin in dairy cows during early lactation. J. Dairy Sci. 92:4439-4443. https://doi.org/ $10.3168 /$ jds.2008-1632.

Kwak-Kim, J., and A. Gilman-Sachs. 2008. Clinical implication of natural killer cells and reproduction. Am. J. Reprod. Immunol. 59:388-400. https://doi.org/10.1111/j.1600-0897.2008.00596.x.

King, K., S. Smith, M. Chapman, and G. Sacks. 2010. Detailed analysis of peripheral blood natural killer (NK) cells in women with recurrent miscarriage. Hum. Reprod. 25:52-58. https://doi.org/10 .1093/humrep/dep349.

Kushibiki, S., K. Hodate, H. Shingu, Y. Obara, E. Touno, M. Shinoda, and Y. Yokomizo. 2003. Metabolic and lactational responses dur- 
ing recombinant bovine tumor necrosis factor-alpha treatment in lactating cows. J. Dairy Sci. 86:819-827.

Lomborg, S. R., L. R. Nielsen, P. M. H. Heegaard, and S. Jacobsen. 2008. Acute phase proteins in cattle after exposure to complex stress. Vet. Res. Commun. 32:575-582. https://doi.org/10.1007/ s11259-008-9057-7.

Macrae, A., and R. Esslemont. 2015. The Prevalence and Cost of Important Endemic Diseases and Fertility in Dairy Herds in the UK. 3rd ed. P. D. Cockcroft, ed. John Wiley \& Sons Ltd., Chichester, UK

March, M. D., L. Toma, W. Stott, and D. J. Roberts. 2016. Modelling phosphorus efficiency within diverse dairy farming systems - Pollutant and non-renewable resource? Ecol. Indic. 69:667-676. https: //doi.org/10.1016/j.ecolind.2016.05.022.

Michou, V. I., P. Kanavaros, V. Athanassiou, G. B. Chronis, S. Stabamas, and V. Tsilivakos. 2003. Fraction of the peripheral blood concentration of $\mathrm{CD} 56+/ \mathrm{CD} 16-/ \mathrm{CD} 3-$ cells in total natural killer cells as an indication of fertility and infertility. Fertil. Steril. 80:691-697. https://doi.org/10.1016/S0015-0282(03)00778-7.

Murata, H., N. Shimada, and M. Yoshioka. 2004. Current research on acute phase proteins in veterinary diagnosis: An overview. Vet. J. 168:28-40. https://doi.org/10.1016/S1090-0233(03)00119-9.

Ohtsuka, H., M. Koiwa, A. Hatsugaya, K. Kudo, F. Hoshi, N. Itoh, H. Yokota, H. Okada, and S. Kawamura. 2001. Relationship between serum TNF activity and insulin resistance in dairy cows affected with naturally occurring fatty liver. J. Vet. Med. Sci. 63:10211025. https://doi.org/10.1292/jvms.63.1021.

Panda, S., and J. L. Ding. 2015. Natural antibodies bridge innate and adaptive immunity. J. Immunol. 194:13-20. https://doi.org/ 10.4049/jimmunol.1400844.

Panndorf, H., H. Richter, and B. Dittrich. 1976. Haptoglobin in domestic mammals. V. Plasma haptoglobin level in cattle under pathological conditions. Arch. Exp. Veterinarmed. 30:193-202.

Ploegaert, T. C., and E. Tijhaar. 2011. Natural antibodies in bovine milk and blood plasma: Variability among cows, repeatability within cows, and relation between milk and plasma titers. Vet. Immunol. Immunpathol. 144:88-94. https://doi.org/10.1016/j vetimm.2011.07.008

Ploegaert, T. C. W., S. Wijga, E. Tijhaar, J. J. van der Poel, T. J. G. M. Lam, H. F. J. Savelkoul, H. K. Parmentier, and J. A. M. van Arendonk. 2010. Genetic variation of natural antibodies in milk of Dutch Holstein-Friesian cows. J. Dairy Sci. 93:5467-5473. https:// doi.org/10.3168/jds.2010-3264.

Seshadri, S., and S. K. Sunkara. 2014. Natural killer cells in female infertility and recurrent miscarriage: A systematic review and me- ta-analysis. Hum. Reprod. Update 20:429-438. https://doi.org/10 .1093/humupd/dmt056.

Sivori, S., M. Vitale, L. Morelli, L. Sanseverino, R. Augugliaro, C. Bottino, L. Moretta, and A. Moretta. 1997. P46, a novel natural killer cell-specific surface molecule that mediates cell activation. J. Exp. Med. 186:1129-1136. https://doi.org/10.1084/jem.186.7.1129.

Smith, B. I., J. Kauffold, and L. Sherman. 2010. Serum haptoglobin concentrations in dairy cattle with lameness due to claw disorders. Vet. J. 186:162-165. https://doi.org/10.1016/j.tvjl.2009.08.012.

Srinivasan, A., Y. Ni, and I. Tizard. 1999. Specificity and prevalence of natural bovine antimannan antibodies. Clin. Diagn. Lab. Immunol. 6:946-952.

Storset, A. K., S. Kulberg, I. Berg, P. Boysen, J. C. Hope, and E. Dissen. 2004. NKp46 defines a subset of bovine leukocytes with natural killer cell characteristics. Eur. J. Immunol. 34:669-676. https://doi.org/10.1002/eji.200324504.

Tassi, R., T. N. McNeilly, J. L. Fitzpatrick, M. C. Fontaine, D. Reddick, C. Ramage, M. Lutton, Y. H. Schukken, and R. N. Zadoks. 2013. Strain-specific pathogenicity of putative host-adapted and nonadapted strains of Streptococcus uberis in dairy cattle. J. Dairy Sci. 96:5129-5145. https://doi.org/10.3168/jds.2013-6741.

Thompson-Crispi, K. A., B. Hine, M. Quinton, F. Miglior, and B. A. Mallard. 2012a. Short communication: Association of disease incidence and adaptive immune response in Holstein dairy cows. J Dairy Sci. 95:3888-3893. https://doi.org/10.3168/jds.2011-5201.

Thompson-Crispi, K. A., A. Sewalem, F. Miglior, and B. A. Mallard 2012 b. Genetic parameters of adaptive immune response traits in Canadian Holsteins. J. Dairy Sci. 95:401-409. https://doi.org/10 .3168/jds.2011-4452.

van Knegsel, A. T. M., G. de Vries Reilingh, S. Meulenberg, H. van den Brand, J. Dijkstra, B. Kemp, and H. K. Parmentier. 2007. Natural antibodies related to energy balance in early lactation dairy cows. J. Dairy Sci. 90:5490-5498. https://doi.org/10.3168/ jds.2007-0289.

van Knegsel, A. T. M., M. Hostens, G. de Vries Reilingh, A. Lammers, B. Kemp, G. Opsomer, and H. K. Parmentier. 2012. Natural antibodies related to metabolic and mammary health in dairy cows. Prev. Vet. Med. 103:287-297. https://doi.org/10.1016/j.prevetmed .2011.09.006.

Veerkamp, R. F., G. Simm, and J. D. Oldham. 1994. Effects of interaction between genotype and feeding system on milk production, feed intake, efficiency and body tissue mobilization in dairy cows. Livest. Prod. Sci. 39:229-241. https://doi.org/10.1016/0301 $-6226(94) 90202-\mathrm{X}$. 